Tema: Metalurgia Secundária

\title{
A EVOLUÇÃO DO EMPREGO DE CARBURETO DE CÁLCIO NO REFINO SECUNDÁRIO DAS SIDERÚRGICAS BRASILEIRAS*
}

\author{
Leonardo Silva Motta ${ }^{1}$ \\ Helio Souza Gabriel ${ }^{2}$ \\ Gilson Menezes ${ }^{3}$ \\ Claudio Schettini ${ }^{4}$ \\ Luis Gustavo Konrath ${ }^{5}$ \\ Ivan Rodrigues Pereira ${ }^{6}$ \\ Amilton Carlos Pinheiro Cardoso Filho ${ }^{7}$ \\ José Cirino do Carmo Filho ${ }^{8}$ \\ Rui Coelho de Assis Filho ${ }^{9}$ \\ Antonio Francisco Martins Barreto ${ }^{10}$
}

\begin{abstract}
Resumo
O carbureto de cálcio tem sido empregado em novas tecnologias para desoxidação e dessulfuração de aços de maneira crescente. A metodologia consiste na realização de um cronograma de projeto contendo dez atividades. Nos últimos anos houve aumento em cerca de $30 \%$ na utilização de carbureto de cálcio na metalurgia secundária das usinas brasileiras. Além desse expressivo aumento, vários trabalhos técnicos são apresentados todos os anos atestando as eficiências técnica, energética e financeira do carbureto de cálcio na produção de aço.

Palavras-chave: Carbureto de cálcio; Refino secundário; Produtividade.

\section{INCREASING EMPLOYMENT OF CALCIUM CARBIDE IN BRAZILIAN SECONDARY REFINIG STEEL}

\begin{abstract}
Calcium carbide has been used in new technologies deoxidation and desulfurization of steel in an increasing manner. The methodology consists in the realization of a project implementation schedule containing ten distinct activities. In recent years there has been an increase of approximately $30 \%$ in the use of calcium carbide in the secondary refining of Brazilian plants. In addition to this significant increase, several technical papers are presented each year certifying the technical, financial and energy efficiencies of calcium carbide in the steel production.
\end{abstract}

Keywords: Calcium carbide; Secondary refining; Productivity.

Engenheiro Metalurgista, Msc., Gerente Processos, White Martins, Membro da ABM, Belo Horizonte, MG, Brasil.

2 Administrador de empresas, Gerente Desenvolvimento Novos Negócios, White Martins, Membro da $A B M$, Itaguama, MG, Brasil.

3 Eng. Metalurgista e Segurança do Trabalho, Ger. Operações Industriais, White Martins, Membro da $A B M$, Itaguama, MG, Brasil.

4 Técnico Metalúrgico, Supervisor de Produção, White Martins, Itaguama, MG, Brasil.

5 Administrador de empresas, Gerente de Negócios, White Martins, Porto Alegre, RS, Brasil.

Administrador de empresas, Gerente de Negócios, White Martins, Volta Redonda, RJ, Brasil.

Engenheiro Metalurgista, Usiminas, Membro da ABM, Belo Horizonte, MG, Brasil.

Administrador de empresas, Supervisor de Forno Panela e Lab. Químico, ArcelorMittal Cariacica, Cariacica, ES, Brasil.

9 Engenheiro de Produção, Assessor Técnico Aciaria, Gerdau Ouro Branco, Membro da ABM, Ouro Branco, MG, Brasil.

10 Engenheiro Metalurgista, Msc., Consultor VSB, AB Consultoria, Jeceaba, MG, Brasil.

* Contribuição técnica ao 45 Seminário de Aciaria - Internacional, 25 a 28 de maio de 2014, Porto Alegre, RS, Brasil. 


\section{INTRODUÇÃO}

A indústria siderúrgica nacional tem enfrentado grandes desafios macroeconômicos desde a crise mundial de 2008. Os maiores "players" internacionais, principalmente chineses, tem aumentado drasticamente a oferta, reduzindo preços e facilitando entregas. A capacidade instalada do parque siderúrgico nacional é maior que a sua demanda interna. Isto dificulta a precificação dos produtos e torna o mercado nacional mais suscetível à agressividade da concorrência externa.

Especialistas apontam caminhos para se combater esta difícil conjuntura. $O$ incentivo à redução de custos operacionais e o aumento da produtividade dos processos são os principais deles.

As empresas têm descoberto que insumos mais eficientes como o carbureto de cálcio podem ser importantes aliados na recuperação de sua competitividade. A sua utilização nas tecnologias de refino secundário tem crescido muito nos últimos anos. Isto se atribui ao aumento das oportunidades para testes, pois o cenário exige disposição para trabalhar eficiência e produtividade de seus processos.

Então, novas oportunidades surgem porque os testes têm apresentado resultados de grande performance.

\section{MATERIAIS E MÉTODOS}

O método utilizado para se empregar o carbureto de cálcio no refino secundário está representado esquematicamente na Figura 1. Ele descreve as etapas padrão para o desenvolvimento de uma tecnologia que utiliza o insumo como agente principal. Consiste em dez atividades divididas em três fases ou grupos: planejamento, experimentação e consolidação dos resultados.

$\mathrm{Na}$ fase de planejamento é estudado o potencial para emprego de uma nova tecnologia e a elaboração de seu procedimento experimental. Normalmente é escolhido um aço ou um grupo de aços de menor complexidade para os primeiros testes. O objetivo é minimizar riscos em caso de insucesso da nova atividade.

Todas as nuances de processo são estudadas previamente. Então, é realizada a fase de experimentação, através de testes a quente. Os resultados mensurados fornecem os subsídios para tomada de decisão da equipe responsável. De posse deles, pode-se concluir o procedimento experimental, padronizando-o ou não, conforme sua performance mensurada. Então, no caso de sucesso, um novo procedimento é inserido nas práticas padrão desta siderúrgica.

O desenvolvimento passa para a fase de consolidação após a padronização do procedimento. Nesta etapa, os experimentos são repetidos em outros produtos ou processos de maiores complexidades, de maneira gradativa, até o preenchimento do portfólio de produtos desta siderúrgica.

Todas as atividades são submetidas às eventuais adequações praticando-se o aperfeiçoamento contínuo, a melhoria contínua.

\footnotetext{
* Contribuição técnica ao 45 Seminário de Aciaria - Internacional, 25 a 28 de maio de 2014 Porto Alegre, RS, Brasil.
} 

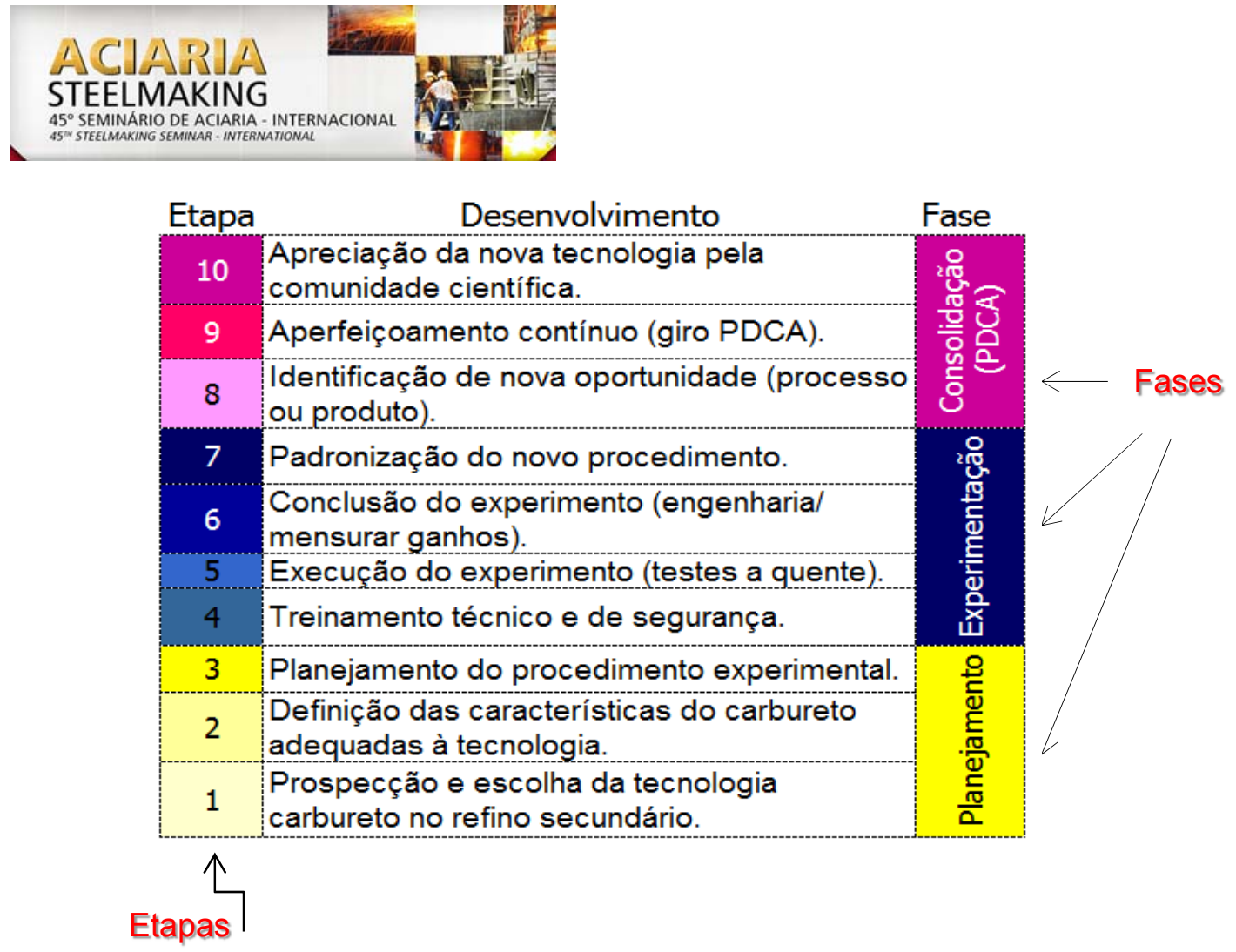

Figura 1. Metodologia adotada para se empregar carbureto no refino secundário.

\subsection{Aspectos de Segurança}

$\mathrm{O}$ carbeto de cálcio $\left(\mathrm{CaC}_{2}\right)$ presente no carbureto reage espontaneamente com a água formando o gás inflamável acetileno $\left(\mathrm{C}_{2} \mathrm{H}_{2}\right)$, nas condições ambiente. Esta reação é apresentada na expressão 1 [1].

$$
\mathrm{CaC}_{2(\mathrm{~s})}+2\left(\mathrm{H}_{2} \mathrm{O}\right)_{(\mathrm{l})} \rightarrow \mathrm{C}_{2} \mathrm{H}_{2(\mathrm{~g})}+\mathrm{Ca}(\mathrm{OH})_{2(\mathrm{~s})}
$$

Em aciarias há fatores de risco como: projeção de fagulhas, proximidade de equipamentos em altas temperaturas, instalações elétricas, dentre outros, que não podem coexistir com o gás acetileno.

Então a principal recomendação do fabricante é: evitar contato do carbureto de cálcio com a água, pois desta maneira, evita-se a presença do acetileno na aciaria.

A ABIQUIM (Associação Brasileira da Indústria Química) e a Resolução 420/04 da ANTT (Agência Nacional de Transportes Terrestres) citam o carbureto de cálcio como produto químico perigoso.

Quando uma equipe de metalurgistas decide-se por testar o carbureto, um treinamento é ministrado para todos os envolvidos. Eles são: operadores, engenheiros, técnicos, brigadistas, pessoal de almoxarifado e outros interessados. Este treinamento é realizado antes da chegada do insumo à usina e é compulsório. Consiste em divulgar todas as informações de segurança documentadas na FISPQ (Ficha de Informação de Produto Químico) e como proceder em caso de uma emergência.

Um simulado de segurança é realizado na siderúrgica, "in loco". O objetivo é reproduzir as diversas situações de risco estudando as características do evento. Ele permite elaborar táticas para prevenção, controle e combate de todos os riscos. O simulado consiste em adicionar água a uma quantidade definida de carbureto e outros materiais inflamáveis como o plástico e madeira, em local apropriado. Uma fonte de ignição é inserida neste sistema e um princípio de incêndio é propositalmente gerado, de maneira controlada. Então todas as características

\footnotetext{
* Contribuição técnica ao 450 Seminário de Aciaria - Internacional, 25 a 28 de maio de 2014, Porto Alegre, RS, Brasil.
} 
visuais são estudadas e as medidas de combate são simuladas. A brigada de incêndio, os técnicos de segurança e o fornecedor do carbureto são obrigatoriamente envolvidos. Todos os EPI's (equipamentos de proteção individual) pertinentes são utilizados e os envolvidos são preparados previamente.

O simulado pode ser substituído pela apresentação de um vídeo quando houver indisponibilidade da empresa ou de qualquer envolvido. Todos os simulados são gravados com o objeto de se multiplicar o conhecimento, principalmente nas indisponibilidades.

A Figura 2 apresenta trecho deste Treinamento de Segurança.

Um dos conceitos abordados é o chamado triangulo do fogo. Para existência da chama é necessária presença simultânea de três agentes: a fonte combustível, fonte comburente e de ignição. A analogia ao triangulo é devido à condição obrigatória e simultânea da existência de três elementos para sua formação.

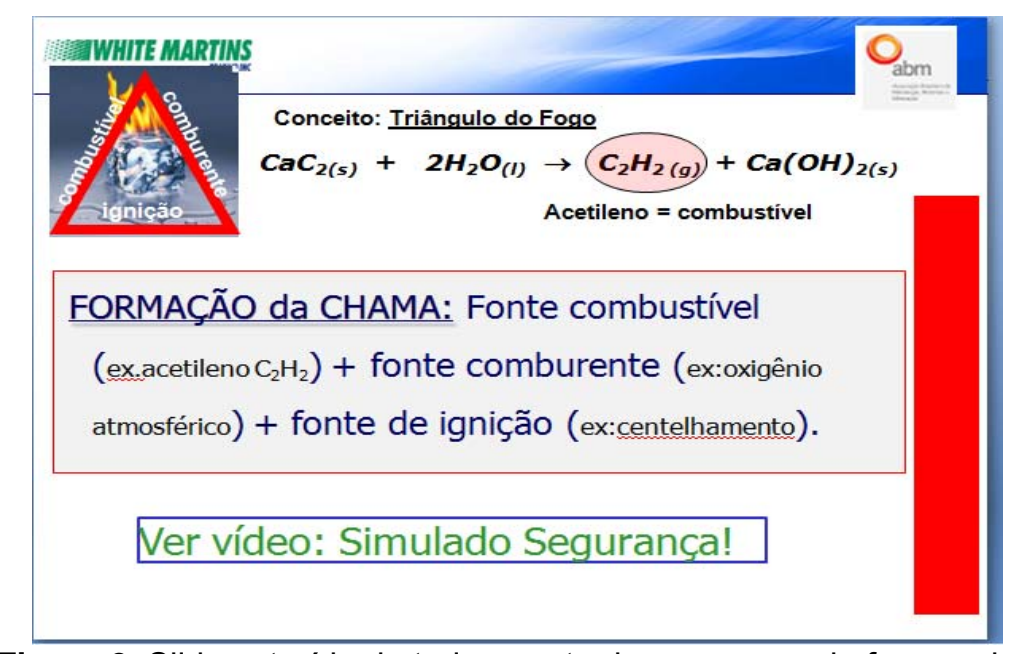

Figura 2. Slide extraído do treinamento de segurança do fornecedor.

Uma das maiores preocupações para se utilizar carbureto de cálcio nas aciarias é a falta de conhecimento para sua melhor utilização. Isto gera riscos à segurança. Estes treinamentos vêm suprir esta necessidade tornando a sua utilização plenamente segura.

É recomendado que o usuário faça o treinamento na periodicidade anual. Ou seja, todos os anos o aciarista, e demais profissionais envolvidos, devem repeti-lo com objetivo de "reciclagem técnica". Além de se praticar a melhoria contínua, nestes momentos, os novatos têm a oportunidade para a sua qualificação.

\section{DISCUSSÕES}

\subsection{Aspectos Químicos}

A Figura 3 apresenta a Classificação Periódica dos Elementos da natureza. Os metais alcalinos terrosos situados na coluna $2 \mathrm{~A}$ desta tabela, como o elemento cálcio, têm afinidade aos elementos da coluna $6 \mathrm{~A}$, como os não metais oxigênio e enxofre. Isto se explica pela teoria elementar das ligações químicas do tipo iônicas [2] (cátions + ânions).

Este princípio químico é uma das justificativas técnicas elementares do emprego de fontes cálcio como agentes desoxidantes e dessulfurantes na metalurgia. As substâncias químicas óxido de cálcio $(\mathrm{CaO})$ e sulfeto de cálcio $(\mathrm{CaS})$ tendem a ser

\footnotetext{
* Contribuição técnica ao 45 Seminário de Aciaria - Internacional, 25 a 28 de maio de 2014, Porto Alegre, RS, Brasil.
} 
mais estáveis comparados aos elementos que os originam. Então o cálcio pode ser capaz, por princípio químico, de extrair oxigênio e enxofre de um aço que os contém dissolvidos.

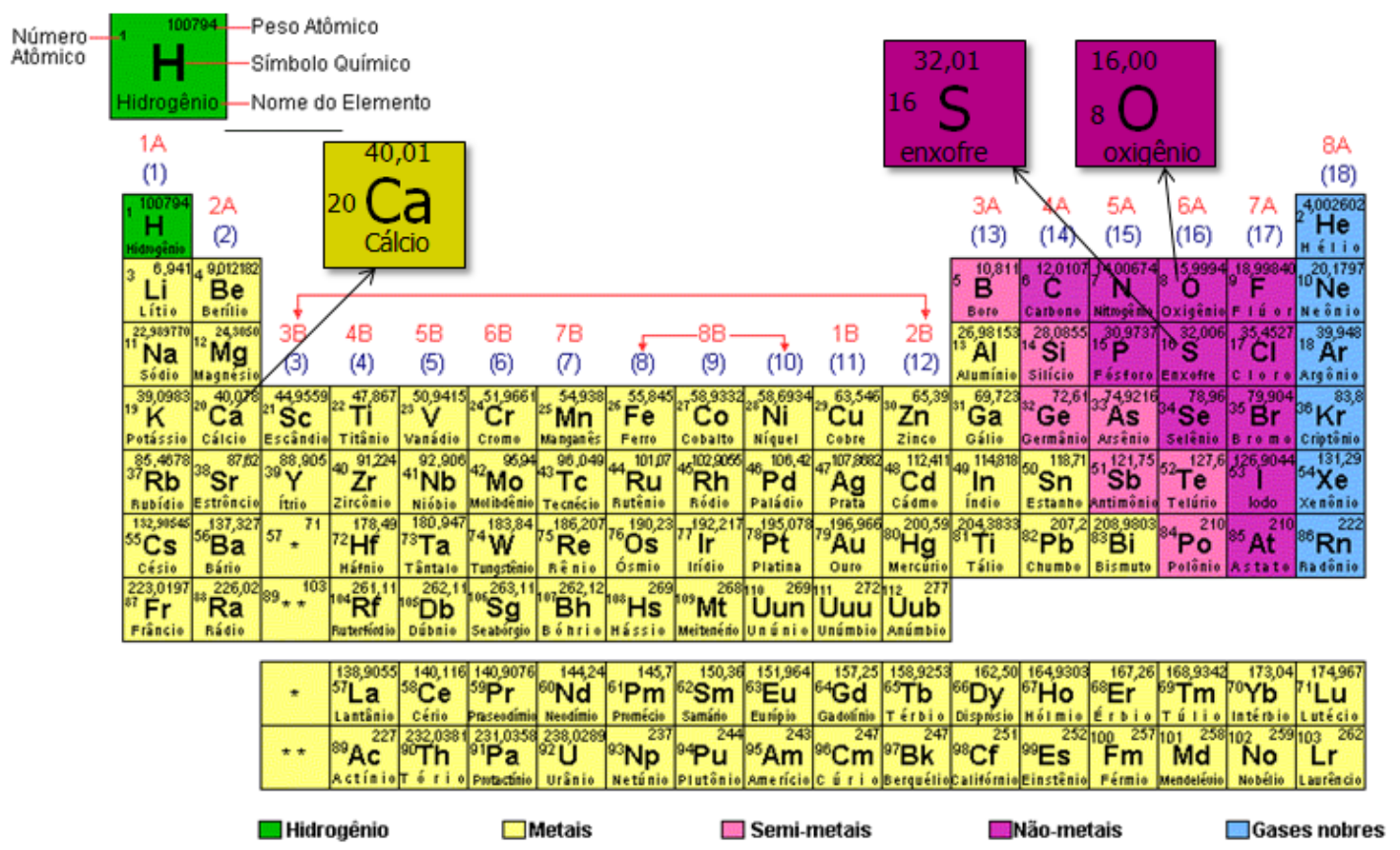

Fonte: http://www.desconversa.com.br/quimica/tag/ametais-tabela-periodica

Figura 3. Destaque do cálcio, oxigênio e enxofre na classificação periódica.

Carbureto de cálcio é um termo comercial. Ele é atribuído a um material constituído de várias substâncias com teores variáveis em solução. As duas principais delas são o $\mathrm{CaC}_{2}$ (carbeto de cálcio) e o $\mathrm{CaO}$ (óxido de cálcio). Há ainda substâncias residuais como o $\mathrm{MgO}$ (óxido de magnésio), $\mathrm{SiO}_{2}$ (óxido de silício), carbono livre e outros, completando $100 \%$ na sua composição.

A composição química final depende dos parâmetros de processo de sua fabricação, da granulometria final e condições atmosféricas de seu ambiente. A Tabela 1 apresenta composição média típica numa amostra cuja faixa granulométrica é bastante difundida no mercado. Esta faixa representa distribuição granulométrica entre o maior $(10 \mathrm{~mm})$ e menor $(2 \mathrm{~mm})$ grão de carbureto classificados por técnica de peneiramento.

Tabela 1. Composição química típica média do carbureto de cálcio

\begin{tabular}{|c|c|c|c|c|c|c|}
\hline $\mathrm{CaC}_{2}(\%)$ & $\mathrm{CaO}(\%)$ & Carbono Livre(\%) & $\mathrm{MgO}(\%)$ & $\mathrm{SiO} 2+\mathrm{Al} 2 \mathrm{O} 3(\%)$ & $\mathrm{Ca}(\%)$ & $\mathrm{C}$ total(\%) \\
\hline 74 & 23 & 0,5 & 1 & 2 & 46 & 28 \\
\hline
\end{tabular}

A presença marcante dos elementos cálcio e carbono na composição do carbureto tornam deste material um agente desoxidante de grande importância.

\subsection{Aspectos Termodinâmicos}

Segundo diagrama de Ellingham [3], também conhecido como diagrama de Jeffs e Richardson [4], o cálcio é termodinamicamente um dos metais com maior potencial de desoxidação nas condições de refino secundário conhecidos. A Figura 4 destaca o diagrama e a representação das reações de oxidação de alguns metais em função

* Contribuição técnica ao 45 Seminário de Aciaria - Internacional, 25 a 28 de maio de 2014, Porto Alegre, RS, Brasil. 
da temperatura. Os estados padrão definidos são: pressão de 1 atmosfera do oxigênio no estado gasoso, o metais puros, sólidos e atividades iguais 1 .

A expressão 2 [5] mostra a reação entre o carbeto de cálcio $\left(\mathrm{CaC}_{2(\mathrm{~s})}\right)$ e o oxigênio dissolvido no aço (ㅁ) $)$. As expressões 3 [3] e 4 [6] mostram a reação entre carbono $(\underline{\mathrm{C}})$ e o oxigênio $(\underline{\mathrm{O}})$ dissolvidos, formando os gases $\mathrm{CO}(\mathrm{CO} \uparrow)$ e $\mathrm{CO}_{2}\left(\mathrm{CO}_{2} \uparrow\right)$.

$$
\begin{aligned}
& \mathrm{CaC}_{2(\mathrm{~s})}+\underline{\mathrm{O}} \rightarrow \mathrm{CaO}_{(\mathrm{l})}+2 \underline{\mathrm{C}} \\
& 2 \underline{\mathrm{C}}+2 \underline{\mathrm{O}} \rightarrow 2 \mathrm{CO} \uparrow \\
& 2 \mathrm{CO} \uparrow+\mathrm{O}_{2} \uparrow \rightarrow 2 \mathrm{CO}_{2} \uparrow
\end{aligned}
$$

$\mathrm{O}$ carbeto de cálcio $\left(\mathrm{CaC}_{2}\right)$ também atua na escória do processo desoxidando os óxidos menos estáveis como os óxidos de ferro e manganês $\left(\mathrm{FeO}_{(\mathrm{l})}\right.$ e o $\left.\mathrm{MnO}_{(\mathrm{I})}\right)$, expressões 5 e 6 [7]. Então, o potencial de oxigênio $\left(\mu \mathrm{O}_{2}\right)$ do sistema (aço + escória) se reduz de maneira rápida, pois os mecanismos ocorrem de maneira simultânea. Assim, o aumento da produtividade do refino secundário pode ser percebido facilmente nos parâmetros de processo mensuráveis.

$$
\begin{aligned}
& \mathrm{CaC}_{2(\mathrm{~s})}+3(\mathrm{FeO})_{(\mathrm{I})} \rightarrow \mathrm{CaO}_{(\mathrm{l})}+2 \mathrm{CO} \uparrow+3 \mathrm{Fe}_{(\mathrm{I})} \\
& \mathrm{CaC}_{2(\mathrm{~s})}+3(\mathrm{MnO})_{(\mathrm{l})} \rightarrow \mathrm{CaO}_{(\mathrm{l})}+2 \mathrm{CO} \uparrow+3 \mathrm{Mn}_{(\mathrm{I})}
\end{aligned}
$$

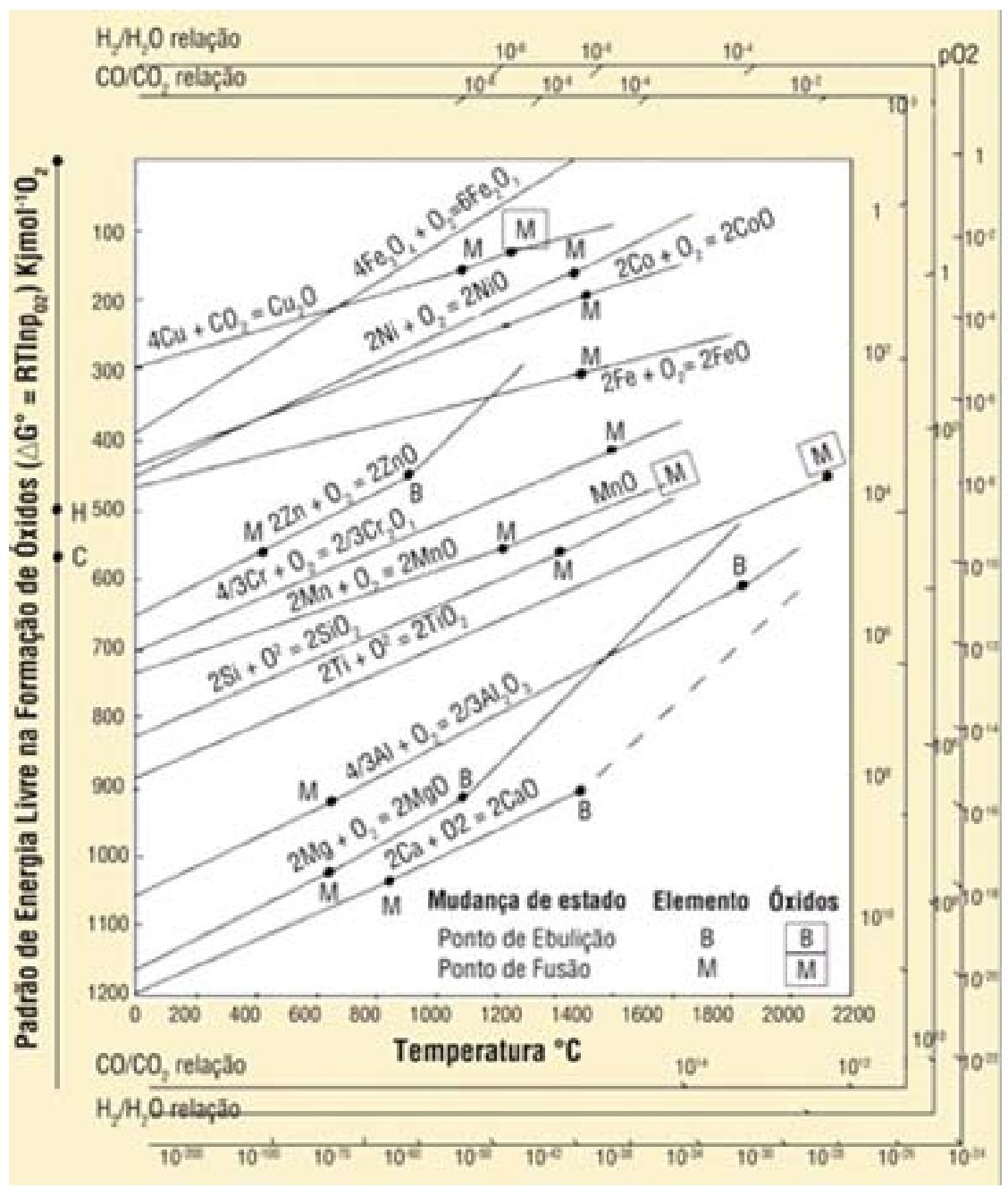

Fonte: htpp//www.revistaih.com.br/coluna/refratarios-e-isolantes-termicos

Figura 4. Diagrama de Ellinghamou Jeffs e Richardson.

* Contribuição técnica ao 450 Seminário de Aciaria - Internacional, 25 a 28 de maio de 2014, Porto Alegre, RS, Brasil. 


\subsection{Aspectos Cinéticos}

O carbono presente no carbureto também é um agente desoxidante eficiente. Ele reage com o oxigênio dissolvido no aço conforme as expressões 3 e 4 . Os produtos gasosos formados $\left(\mathrm{CO}\right.$ e $\left.\mathrm{CO}_{2}\right)$ geram gradientes em suas pressões parciais provocando agitação natural em todo o sistema (aço, escória e gases dissolvidos). Esta agitação complementar favorece a cinética global porque contribui à interação entre as fases e reduz a resistência das interfaces. Este fenômeno é conhecido como "auto-stirring" ou a auto agitação.

O "auto-stirring" torna a desoxidação de aço e escória pelo carbureto de cálcio um processo mais favorável cineticamente.

Com isso, as reações geradas tendem a ser favoráveis para a metalurgia secundária nos seus aspectos: químico, termodinâmico e cinético. Os vários mecanismos de desoxidação que agem simultaneamente: a ação do carbeto de cálcio $\left(\mathrm{CaC}_{2}\right)$, do carbono e do gás $\mathrm{CO}$ (monóxido de carbono), contribuem significativamente na produtividade afetando o custo final.

Além disso, o emprego do carbureto evita a formação de óxidos indesejáveis. Eles são críticos para o processo porque geram efeito "clogging" ou obstrução da válvula submersa durante o processo de lingotamento contínuo. Isto prejudica a qualidade dos produtos, a produtividade e o custo final do processo. A substituição parcial do alumínio pelo carbureto de cálcio reduz a formação de alumina, que é de difícil remoção, favorecendo a limpidez do aço [7].

\subsection{Efeito Sob a Escória}

O processo de desoxidação pelo carbureto afeta as propriedades da escória do aço tratado. A sua basicidade binária $\left(\mathrm{CaO} / \mathrm{SiO}_{2}\right)$ aumenta pois há formação de óxido de cálcio( $\mathrm{CaO})$ expressão 2. Além disso, gases dissolvidos $\left(\mathrm{CO}\right.$ e $\left.\mathrm{CO}_{2}\right)$ reduzem a sua densidade durante o processo. A cinética de reação é potencializada pelo "autostirring" que aumenta a interação entre as fases envolvidas e reduz a resistência da interface escória-aço aumentando sua homogeneidade. A escória com aparência mais "espumosa" é menos viscosa facilitando todo o processo. A combinação de escória espumosa e homogeneização do sistema favorecem a velocidade de redução do $\mathrm{FeO}$ e $\mathrm{MnO}$ na escória, expressões 5 e 6 . Esta combinação também reduz a reoxidação do aço e o consumo de energia elétrica no forno panela [8], além de melhorar a lingotabilidade do aço (redução do efeito clogging).

O resultado é um ganho expressivo de produtividade e grande número de benefícios complementares no processo global. A Figura 5 mostra fotografia típica de uma escória espumosa tratada com carbureto de cálcio no refino secundário [1].

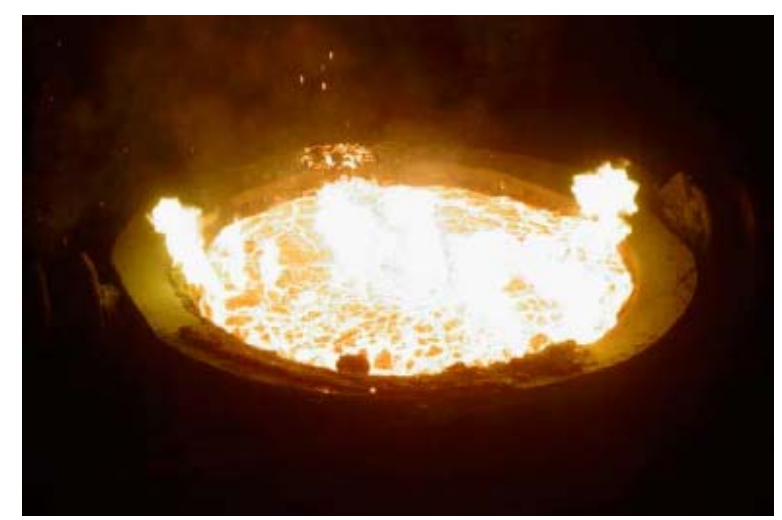

Figura 5. Foto destacando escória espumosa do refino secundário em uma aciaria [1].

* Contribuição técnica ao 45 Seminário de Aciaria - Internacional, 25 a 28 de maio de 2014, Porto Alegre, RS, Brasil. 
Estes fatores agregados também favorecem a chamada desoxidação seletiva. 0 carbureto de cálcio sendo agente desoxidante forte e sua cinética beneficiada pela agitação complementar ou "auto-stirring" permitem reduzir o consumo de ligas. É possível desoxidar o aço preferencialmente pelo carbureto evitando ou minimizando a desoxidação pelas ligas adicionadas que possuem outra finalidade. As ligas são adicionadas ao processo com objetivo de se alcançar à composição química especificada $e$ as propriedades finais de seus produtos. Ao se praticar a desoxidação seletiva o efeito é a redução do consumo destas ligas. Além disso, a agitação complementar, fruto desta nova tecnologia, tende a melhorar o rendimento físico delas. Os dois efeitos ocorrem simultaneamente e vêm afetar fortemente o consumo reduzindo o custo do processo produtivo. Ao se produzir aços cuja demanda por ligas é maior o potencial de economia nos processos carbureto cresce. Ou seja, quanto maior o valor agregado do produto siderúrgico maior é a economia de seu processo utilizando carbureto de cálcio no refino.

\subsection{O Processo de Dessulfuração}

Pode-se avaliar qualitativamente o potencial de dessulfuração de uma escória pelo estudo das expressões 7 e 8 [9]. Elas mostram que a dessulfuração de um processo é favorecida pelo aumento da atividade do $\mathrm{CaO}$ (aumento da basicidade) na escória, o aumento da temperatura e a redução do potencial de oxidação $\left(\mu \mathrm{O}_{2}\right)$ deste sistema [9]. Assume-se a conservação dos demais parâmetros.

$$
\begin{array}{r}
C a O_{(s)}+\underline{S} \rightarrow \operatorname{CaS}_{(l)}+\frac{1}{2} O_{2(g)} \\
\ln \% S=\frac{\Delta G^{o}}{R T}+\ln a_{C a S}-\ln a_{C a O}+\frac{\mu_{O_{2}}}{2 R T}-\ln f_{S}
\end{array}
$$

Analogamente, o carbureto de cálcio utilizado como agente desoxidante terá efeito dessulfurante. Isto porque as reações de desoxidação do carbureto aumentam atividade do $\mathrm{CaO}$ na escória, expressão 2, e reduz o potencial de oxigênio no sistema, expressões 2,3 e 4. A dessulfuração é processo que depende muito de fatores cinéticos, pois necessita de uma interação eficiente entre a escória e o banho. Então, o "auto-stirring" também assume papel importante, pois contribuirá significativamente no sentido de favorecer os dois mecanismos.

Os efeitos combinados do poder de desoxidação e dessulfuração tornam o carbureto de cálcio um importante insumo para o refino secundário. Seu efeito no sistema (aço+escória) é capaz de produzir resultados significativos de maneira simultânea.

\section{RESULTADOS}

Vários trabalhos têm sido publicados todos os anos, em fóruns internacionais. Eles atestam a eficiência do carbureto de cálcio em processos de refino secundário. Os resultados mostrados têm surpreendido positivamente.

O aumento da carga de aço tratado com carbureto de cálcio no Brasil nos últimos anos é justificado pela evidência destes benefícios. A Figura 6 apresenta um gráfico da estimativa da carga total de aço tratado com carbureto nas siderúrgicas brasileiras nos últimos onze anos. Nos últimos três anos houve aumento em aproximadamente $30 \%$ da carga de aço tratado com carbureto de cálcio no refino secundário no Brasil.

\footnotetext{
* Contribuição técnica ao 45 Seminário de Aciaria - Internacional, 25 a 28 de maio de 2014, Porto Alegre, RS, Brasil.
} 

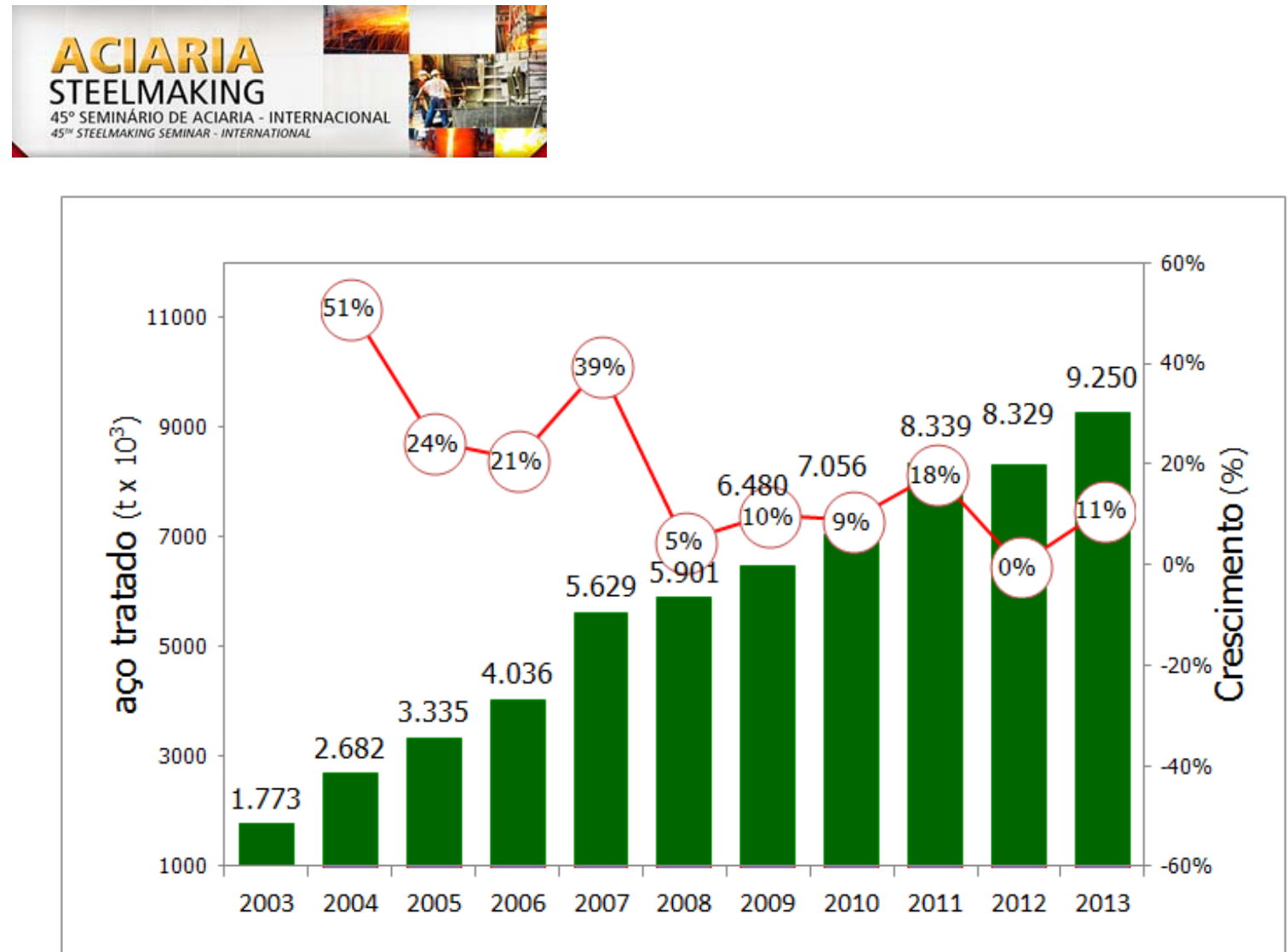

Figura 6. Evolução da utilização de carbureto de cálcio no Brasil. Carga de aço produzida em $10^{3}$ toneladas e crescimento percentual (\%) no tempo (ano).

Algumas das principais usinas siderúrgicas brasileiras destacam benefícios tecnológicos do advento das tecnologias carbureto:

- Siderúrgica 1 [1]: melhoria substancial da limpidez aços peritéticos, redução da ocorrência obstrução válvulas submersas aumentando a lingotabilidade.

- Siderúrgica 2 [3]: redução do custo produtivo, redução consumo de ligas, melhoria de rendimento metálico, aumento da competitividade dos produtos siderúrgicos de seu portfólio.

- Siderúrgica 3 [5]: obtenção de aços com teores de enxofre abaixo dos 40ppm, aumento dos rendimentos das ligas ferro silício e ferro cromo, melhoria da qualidade intrínseca do produto acabado e aumento da produtividade global da aciaria.

- Siderúrgica 4 [7]: melhoria na eficiência da desoxidação da escória, aumento do rendimento do alumínio e aumento da limpidez dos aços acabados.

- Siderúrgica 5 [8]: melhoria nos processos de refino secundário e na composição de escória tratada.

- Siderúrgica 6 [10]: aumento da taxa de dessulfuração dos aços empregados.

\section{CONCLUSÃO}

O emprego do carbureto de cálcio nas siderúrgicas brasileiras tem crescido significativamente nos últimos anos. Tanto o número de aços produzidos quanto a quantidade de empresas siderúrgicas utilizando tecnologias carbureto têm evoluído substancialmente. Este fato irrefutável vem de encontro ao difícil momento por que passa este setor por fatores de ordem macroeconômica. As empresas têm utilizado este insumo como um aliado importante para a recuperação de sua competitividade. Mas isto só é possível graças ao grande potencial técnico deste insumo principalmente nos processos de dessulfuração e desoxidação do refino secundário.

\footnotetext{
* Contribuição técnica ao 450 Seminário de Aciaria - Internacional, 25 a 28 de maio de 2014, Porto Alegre, RS, Brasil.
} 
O carbureto de cálcio tem mostrado que eficiências técnica, energética e financeira (sustentabilidade) são temas atuais, necessários e, sobretudo, possíveis.

\section{REFERÊNCIAS}

1 C Filho ACP, Souza CA, Athaide Jr. JDG, Freitas PA, Rocha SH, Menezes GA, et al. Desenvolvimento da técnica de desoxidação do aço utilizando carbureto de cálcio na Usiminas. In: ABM. $42^{\circ}$ Seminário de Aciaria - Internacional; 20-23 mai. 2011; Belo Horizonte, Brasil. São Paulo: ABM; 2011.

2 Lembo A. Química realidade e contexto - vol.1. São Paulo: Editora Atica;1999. p153160.

3 Bruch R. Estudo termodinâmico da desoxidação do aço escória com a adição de carbureto de cálcio. Porto Alegre: UFRS; 2006.

4 Gaskell DR. Introduction to metallurgical thermodynamics. Tokyo: Mcgraw-Hill Hogakusha; 1973.

5 Campos AA, Lana AB, Cavalieri ES, Athaide Jr. JDG, Pinto JE, Ank JG, et. al. Desoxidação e dessulfuração dos aços carbono e ligados com a utilização de $\mathrm{CaC}_{2}$. In: ABM. 39 Seminário de Aciaria - Internacional; 12-16 mai. 2008; Curitiba, Brasil. São Paulo: ABM; 2008.

6 Campos VF. Tecnologia de fabricação do aço líquido; fundamentos. Belo Horizonte: Universidade Federal de Minas Gerais; 1980. 31p.

7 Giacomin RC, Fujii T, Barreto AFM, Bras TF. Melhorando limpidez de aços através da prática de desoxidação no vazamento do forno elétrico a arco. In: ABM. $44^{\circ}$ Seminário de Aciaria - Internacional; 26-29 mai. 2013; Araxá, Brasil. São Paulo: ABM; 2013.

8 Maia BT, Monteiro FL, Menezes GA, Souza HG, Carvalho NJ. Implantação da desoxidação do aço durante o vazamento com uso de carbureto de cálcio. In: $37^{\circ}$ Seminário de Aciaria - Internacional; 22-24 mai. 2006; Porto Alegre, Brasil. São Paulo: ABM; 2006.

9 Castro LF, Assis PS, Camilo RD, Fiqueira RM, Campos VF. Termodinâmica aplicada. Belo Horizonte: UFMG; 2002.

10 Campos JMG, Coelho MTSF, Rochelle CED, Amaral EA, Barros NM, Ribeiro DB, et al. Dessulfuração na aciaria da ArcelorMittal Piracicaba. In: $39^{\circ}$ Seminário de Aciaria Internacional; 12-16 mai. 2008; Curitiba, Brasil. São Paulo: ABM; 2008.

* Contribuição técnica ao 45 Seminário de Aciaria - Internacional, 25 a 28 de maio de 2014, Porto Alegre, RS, Brasil. 